\title{
Optimized Protocol for In Vitro Pollen Germination in Yam (Dioscorea spp.)
}

\author{
Jean M. Mondo ${ }^{1,2,3} \mathbb{D}^{\mathbb{D}}$, Paterne A. Agre ${ }^{1, * \mathbb{D}}$, Robert Asiedu ${ }^{1}$, Malachy O. Akoroda ${ }^{4}$ and Asrat Asfaw ${ }^{1} \mathbb{D}$ \\ 1 International Institute of Tropical Agriculture (IITA), Ibadan 5320, Nigeria; m.mubalama@cgiar.org (J.M.M.); \\ r.asiedu@cgiar.org (R.A.); a.amele@cgiar.org (A.A.) \\ 2 Institute of Life and Earth Sciences, Pan African University, University of Ibadan, Ibadan 200284, Nigeria \\ 3 Department of Crop Production, Université Evangélique en Afrique (UEA), \\ Bukavu 3323, Democratic Republic of the Congo \\ 4 Department of Agronomy, University of Ibadan, Ibadan 200284, Nigeria; malachyoakoroda@gmail.com \\ * Correspondence: p.agre@cgiar.org
}

Citation: Mondo, J.M.; Agre, P.A.; Asiedu, R.; Akoroda, M.O.; Asfaw, A. Optimized Protocol for In Vitro Pollen Germination in Yam (Dioscorea spp.). Plants 2021, 10, 795. https:// doi.org/10.3390/plants10040795

Academic Editor: Agnes Farkas

Received: 30 March 2021

Accepted: 16 April 2021

Published: 18 April 2021

Publisher's Note: MDPI stays neutral with regard to jurisdictional claims in published maps and institutional affiliations.

Copyright: (c) 2021 by the authors. Licensee MDPI, Basel, Switzerland. This article is an open access article distributed under the terms and conditions of the Creative Commons Attribution (CC BY) license (https:// creativecommons.org/licenses/by/ $4.0 /)$.

\begin{abstract}
Yam (Dioscorea spp.) plants are mostly dioecious and sometimes monoecious. Low, irregular, and asynchronous flowering of the genotypes are critical problems in yam breeding. Selecting suitable pollen parents and preserving yam pollen for future use are potential means of controlling these constraints and optimizing hybridization practice in yam breeding programs. However, implementing such procedures requires a robust protocol for pollen collection and viability testing to monitor pollen quality in the field and in storage. This study, therefore, aimed at optimizing the pollen germination assessment protocol for yam. The standard medium composition was stepwisely modified, the optimal growth condition was tested, and in vivo predictions were made. This study showed that the differences in yam pollen germination percentage are primarily linked to the genotype and growing conditions (i.e., medium viscosity, incubation temperature, and time to use) rather than the medium composition. The inclusion of polyethylene glycol (PEG) in the culture medium caused $67-75 \%$ inhibition of germination in D. alata. Although the in vivo fertilization was dependent on female parents, the in vitro germination test predicted the percentage fruit set at $25.2-79.7 \%$ and $26.4-59.7 \%$ accuracy for $D$. rotundata and D. alata genotypes, respectively. This study provides a reliable in vitro yam pollen germination protocol to support pollen management and preservation efforts in yam breeding.
\end{abstract}

Keywords: Brewbaker and Kwack medium; D. alata; D. rotundata; pollen viability and storage; in vivo fertilization

\section{Introduction}

The yam is a multispecies crop belonging to the genus Dioscorea and provides food, medicine, and income in tropical and subtropical areas of America, Africa, Asia, the Caribbean, and Oceania [1]. Of the $\sim 600$ yam species, white yam (D. rotundata Poir.), yellow yam (D. cayenensis Lam.) and water yam (D. alata L.) represent $\sim 95 \%$ of the global yam production [2]. Six African countries, namely Nigeria, Ghana, Côte d'Ivoire, Benin, Togo and Cameroon, account for more than $90 \%$ of the annual global yam production [3]. In these countries, yam is not only a food and income security crop; it is also an integral part of the people's socio-cultural and religious belief systems.

Most popular yam species are predominantly dioecious, with male and female flowers borne on separate individual plants. Indeed, individuals of a yam cultivar are unisexual (being either male or female) although cases of monoecious plants (individuals with both male and female flowers) exist [4-6]. Developing new yam varieties requires, therefore, hybridization among selected parents to create genetic variability and selection of the progenies' superior clonal derivatives for release after a series of testing. Successful hybridization depends primarily on the pollen germination ability (viability) of the male 
parent and the stigma receptivity of the female under favorable weather conditions [6]. In this work, two aspects of pollen viability are discussed: the pollen's germination ability tested in the laboratory, and its ability to fertilize a female flower after hand pollination [7].

Yam hybridization activities are often constrained by low, irregular and asynchronous flowering $[5,6]$. Selecting suitable pollen parents and preserving yam pollen for future use are potential means of managing these constraints $[6,8]$. However, implementing these practices in yam breeding programs requires a cost-effective and reliable pollen viability testing protocol, allowing the discrimination of genotypes for viability status and efficient monitoring of stored pollen.

Past studies on yam pollen used viability (germination) testing protocols from other crops without prior optimization [8-10], which led to a low uptake by the breeding programs. There is, therefore, a need to develop an optimized pollen viability testing method for yam to increase pollination efficiency, facilitate efficient monitoring of stored pollen and for genetic and physiological studies. Mondo et al. [6] reviewed the most popular pollen viability testing methods and their potential in improving pollination efficiency in yam breeding programs. These include in vitro germination, the vital staining of pollen grains, in vivo fertilization and seed development, and impedance or optical flow cytometry. In vitro germination method consists of assessing the germination of pollen on a nutritive medium. This method is highly correlated with in vivo pollination for most crops. For instance, $\mathrm{Ng}$ and Daniel [10] established a positive relationship between in vitro germination and fruit set after hand pollination of white Guinea yam (D. rotundata). That positive relationship was also confirmed on other plant species by Volk [11]. Mondo et al. [6] suggested that the Brewbaker and Kwack [12] culture medium previously used in yam pollen studies should be optimized for the concentration of the boric acid, calcium nitrate, sucrose and the $\mathrm{pH}$ as requirements vary with species. The effects of other factors such as the type of medium (semi-solid or liquid), germination temperature, incubation duration and the inclusion of polyethylene glycol in the medium on pollen germination have not been determined for yam and should, therefore, be investigated for the optimum in vitro germination testing.

This work aimed at establishing a pollen germination assessment protocol by determining the optimal germination medium composition for yam pollen and suitable growth conditions.

\section{Results}

The development of the pollen germination protocol for yam was achieved in three steps. We first identified the optimum growing conditions after assessing effects of incubation duration and temperature, medium viscosity (levels of the agar concentration), and delay in the use of collected pollen. Best growing conditions were then used in optimizing the medium composition through a series of single-factor experiments. Lastly, we assessed the prediction ability of the optimized protocol vis-à-vis in vivo fertilization using a series of hand pollinations.

\subsection{Growth Conditions and Pollen Germination Percentage}

Increasing the time interval between pollen collection and culture negatively affected the pollen germination ability $(p<0.001)$. About $50-75 \%$ germination ability was lost in 3-4 h after pollen collection from the field, regardless of the genotype (Figure 1). The agar concentration and the genotype significantly affected the $D$. rotundata pollen grain germination $(p<0.001)$. The highest mean germination levels were recorded on $0.5 \%$ (14.2\% germination) and $1 \%$ (13.5\% germination) of agar, while the lowest $(4.9 \%)$ was on the hanging drop without agar. TDr1621001 pollen grains germinated at a higher rate $(17.4 \%)$ than those of TDr1655018 (4.7\%) (Table 1). Other factors, such as the incubation temperature and duration had no significant effects on germination percent. However, the interactions genotype $\times$ temperature $(p=0.02)$, genotype $\times$ agar $(p<0.001)$, temperature $\times$ agar $(p=0.005)$, and genotype $\times$ temperature $\times$ agar $(p<0.001)$ were significant. 


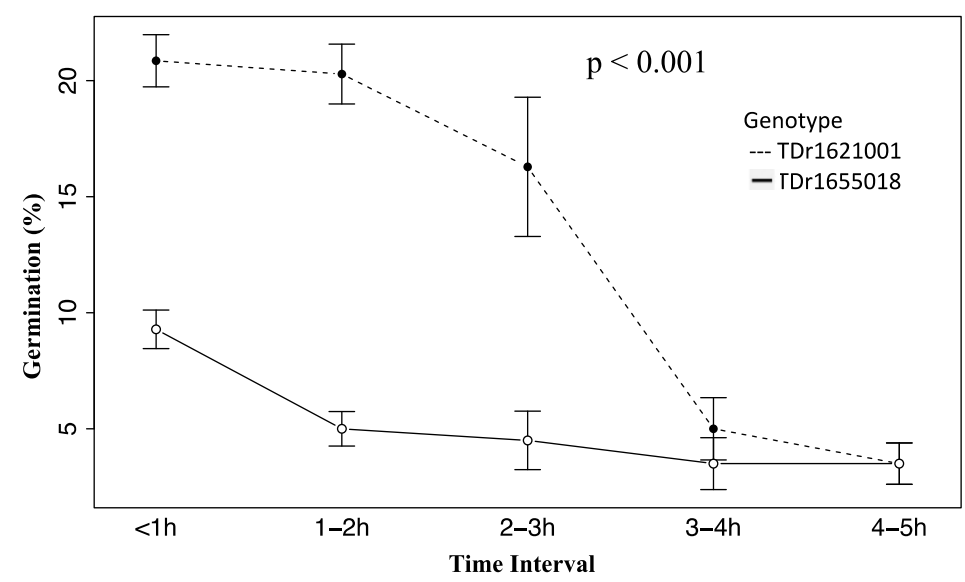

Figure 1. Effect of the delay between pollen collection and culture on percentage germination of two D. rotundata genotypes $(p<0.001)$.

Table 1. Effects of the interactions between the incubation duration and temperature and the agar concentration on percentage germination of pollen from two D. rotundata genotypes.

\begin{tabular}{|c|c|c|c|c|c|c|c|c|c|c|}
\hline \multirow{2}{*}{ Genotype } & \multirow{2}{*}{$\begin{array}{c}\text { Incubation Duration } \\
\text { Agar Concentration (\%) }\end{array}$} & \multicolumn{4}{|c|}{$3 \mathrm{~h}$} & \multicolumn{4}{|c|}{$18 \mathrm{~h}$} & \multirow{2}{*}{ Mean } \\
\hline & & 0 & 0.5 & 0.75 & 1 & 0 & 0.5 & 0.75 & 1 & \\
\hline \multirow{3}{*}{ TDr1621001 } & $15^{\circ} \mathrm{C}$ & 3.0 & 18.0 & 18.0 & 26.0 & 4.0 & 19.0 & 19.0 & 25.0 & $16.5^{\mathrm{a}}$ \\
\hline & $25^{\circ} \mathrm{C}$ & 4.0 & 17.0 & 24.0 & 17.0 & 9.0 & 17.0 & 29.0 & 19.0 & $17.0^{\mathrm{a}}$ \\
\hline & $35^{\circ} \mathrm{C}$ & 6.0 & 29.0 & 17.0 & 21.0 & 7.0 & 30.0 & 18.0 & 21.0 & $18.6^{\mathrm{a}}$ \\
\hline \multirow{4}{*}{ TDr1655018 } & $15^{\circ} \mathrm{C}$ & 2.0 & 10.0 & 7.0 & 8.0 & 6.0 & 11.0 & 7.0 & 8.0 & $7.4^{b}$ \\
\hline & $25^{\circ} \mathrm{C}$ & 4.0 & 2.0 & 2.0 & 10.0 & 5.0 & 6.0 & 2.0 & 10.0 & $5.1^{b c}$ \\
\hline & $35^{\circ} \mathrm{C}$ & 0.0 & 4.0 & 3.0 & 5.0 & 3.0 & 6.0 & 4.0 & 9.0 & $4.2^{\mathrm{c}}$ \\
\hline & Mean & $3.2^{c}$ & $13.3^{\mathrm{ab}}$ & $11.8^{b}$ & $14.5^{\mathrm{ab}}$ & $5.7^{c}$ & $14.8^{\mathrm{a}}$ & $13.2^{\mathrm{ab}}$ & $15.3^{a}$ & \\
\hline
\end{tabular}

$p<0.001$ for the genotype and the agar concentration; $p=0.06$ and 0.63 for the incubation duration and temperature, respectively. $\mathrm{LSD}_{0.05}=1.5$ (genotype); $\mathrm{LSD}_{0.05}=2.1$ (agar). Means followed by the same letter in the column/row do not differ by the LSD test at $5 \%$ $p$-value threshold. Further, 15,25 and $35^{\circ} \mathrm{C}$ represent the three levels of incubation temperature.

Dioscorea alata pollen germination was sensitive to the temperature $(p=0.034)$, the agar concentration $(p<0.001)$ and the genotype effects $(p<0.001)$. The best results were recorded on the medium with 0.5 and $0.75 \%$ agar (14.9 and $11.3 \%$ germination, respectively). The liquid medium (without agar) had the lowest germination (Table 2) consistently. Pollen grains from TDa1662006 germinated better than those from TDa1662010 (12.7 vs. 6.6\%). The optimum pollen germination temperature for $D$. alata was $25{ }^{\circ} \mathrm{C}$.

Table 2. Effects of the interactions between the incubation duration and temperature and the agar concentration on percentage germination of pollen from two D. alata genotypes.

\begin{tabular}{|c|c|c|c|c|c|c|c|c|c|c|}
\hline \multirow{2}{*}{ Genotype } & \multirow{2}{*}{$\begin{array}{c}\text { Incubation Duration } \\
\text { Agar Concentration (\%) }\end{array}$} & \multicolumn{4}{|c|}{$3 \mathrm{~h}$} & \multicolumn{4}{|c|}{$18 \mathrm{~h}$} & \multirow{2}{*}{ Mean } \\
\hline & & 0 & 0.5 & 0.75 & 1 & 0 & 0.5 & 0.75 & 1 & \\
\hline \multirow{3}{*}{ TDa1662006 } & $15^{\circ} \mathrm{C}$ & 6.0 & 18.0 & 5.0 & 4.0 & 6.0 & 20.0 & 6.0 & 4.0 & $8.6^{\mathrm{ns}}$ \\
\hline & $25^{\circ} \mathrm{C}$ & 5.0 & 21.0 & 26.0 & 12.0 & 5.0 & 22.0 & 29.0 & 16.0 & $17.0^{\mathrm{ns}}$ \\
\hline & $35^{\circ} \mathrm{C}$ & 7.0 & 11.0 & 12.0 & 12.0 & 7.0 & 19.0 & 17.0 & 14.0 & $12.4^{\mathrm{ns}}$ \\
\hline \multirow{4}{*}{ TDa1662010 } & $15^{\circ} \mathrm{C}$ & 4.0 & 5.0 & 4.0 & 4.0 & 6.0 & 10.0 & 6.0 & 5.0 & $5.5^{\mathrm{ns}}$ \\
\hline & $25^{\circ} \mathrm{C}$ & 3.0 & 11.0 & 6.0 & 7.0 & 6.0 & 12.0 & 5.0 & 5.0 & $6.9^{\mathrm{ns}}$ \\
\hline & $35^{\circ} \mathrm{C}$ & 2.0 & 16.0 & 10.0 & 3.0 & 2.0 & 14.0 & 10.0 & 3.0 & $7.5^{\mathrm{ns}}$ \\
\hline & Mean & $4.5^{\mathrm{ns}}$ & $13.7^{\mathrm{ns}}$ & $10.5^{\mathrm{ns}}$ & $7.0^{\mathrm{ns}}$ & $5.3^{\mathrm{ns}}$ & $16.2^{\mathrm{ns}}$ & $12.2^{\mathrm{ns}}$ & $7.8^{\mathrm{ns}}$ & \\
\hline
\end{tabular}

Agar $(p<0.001)$; genotype $(p<0.001)$; temperature $(p=0.0348) . \quad \mathrm{LSD}_{0.05}=4.24$ (agar); 2.99 (incubation duration); 3.0 (genotype); 3.67 (temperature). All the interactions' effects were not significant (ns). Further, 15,25 and $35^{\circ} \mathrm{C}$ represent the three levels of incubation temperature. 


\subsection{Medium Composition and Pollen Germination}

In all the single-factor experiments (Figures 2-5), the percent pollen germination differences were exclusively under the genotype effects for both yam species. For $D$. rotundata, pollen of TDr1621012 always had higher percent germination than TDr1655018 (25.2-44.0 vs. $6.2-13.2 \%)$. The trend was similar for D. alata; pollen of TDa1662006 had consistently higher percent germination (31.5-39.6\%) compared to TDa1662010 (9.8-11.2\%).
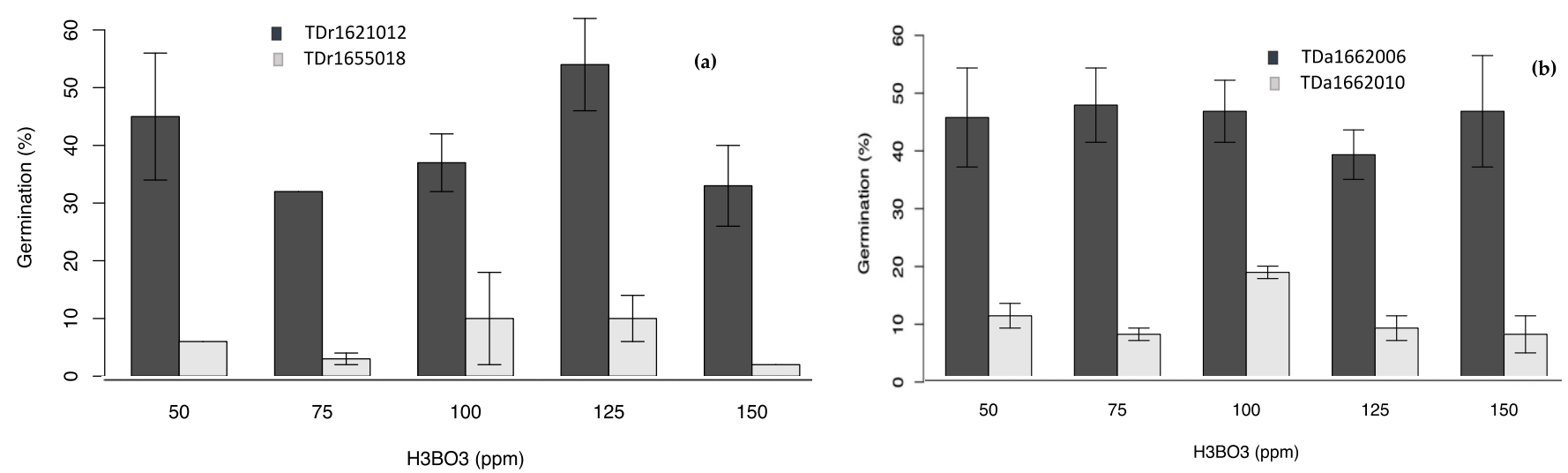

Figure 2. Effects of boric acid on pollen germination of genotypes of (a) D. rotundata, (b) D. alata.
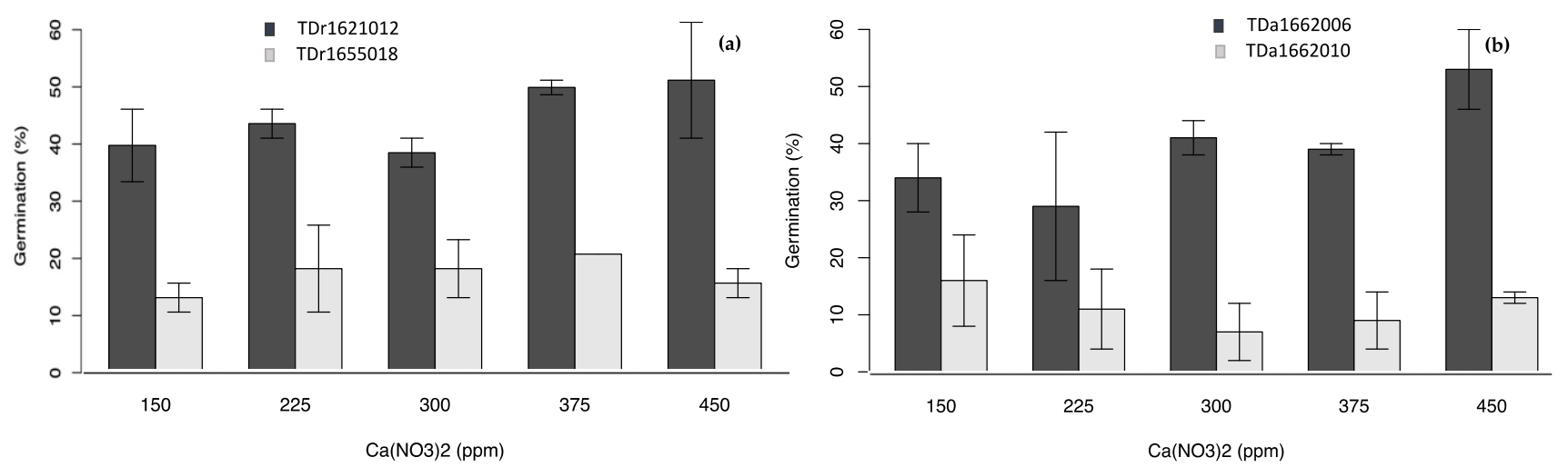

Figure 3. Effects of calcium nitrate on pollen germination of genotypes of (a) D. rotundata, (b) D. alata.
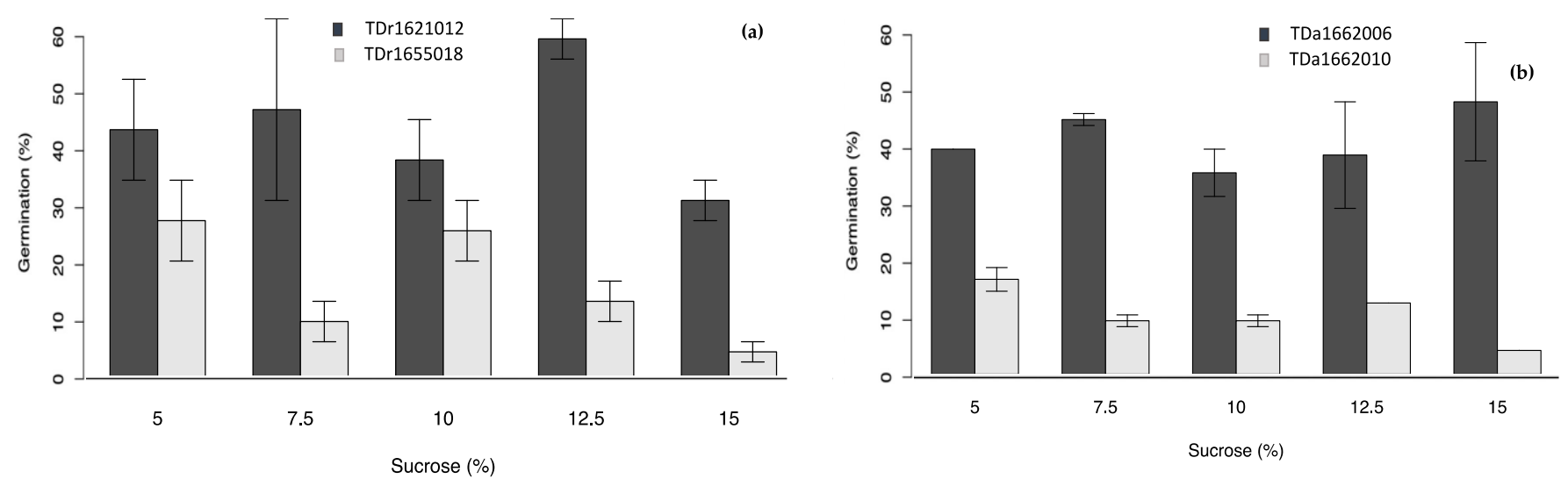

Figure 4. Effects of sucrose on pollen germination of genotypes of (a) D. rotundata, (b) D. alata. 

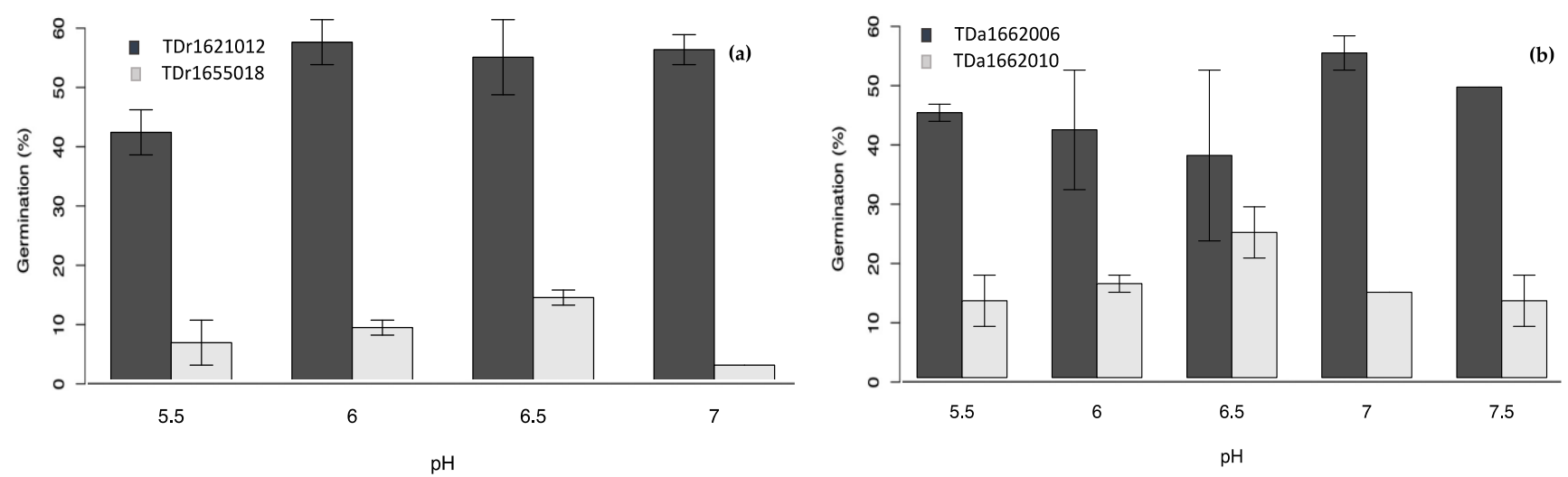

Figure 5. Effects of the medium $\mathrm{pH}$ on pollen germination of genotypes of (a) D. rotundata, (b) D. alata.

\subsection{Effects of Polyethylene Glycol on Yam Pollen Germination}

The best single-factor experiments' composition media were selected to evaluate the effects of polyethylene glycol (PEG) on percent yam pollen germination. For D. rotundata, the medium composition at this stage was: $12.5 \%$ sucrose, $125 \mathrm{ppm}$ boric acid, $375 \mathrm{ppm}$ calcium nitrate, and adjusted at $\mathrm{pH}$ 6.5. On the other hand, the medium composition for D. alata was made of: $5 \%$ sucrose, $100 \mathrm{ppm}$ boric acid, $450 \mathrm{ppm}$ calcium nitrate, and adjusted at $\mathrm{pH}$ 7. All other medium ingredients $\left(\mathrm{MgSO}_{4} \cdot 7 \mathrm{H}_{2} \mathrm{O}\right.$ and $\left.\mathrm{KNO}_{3}\right)$ not optimized in this study were kept at the same concentrations as in the Brewbaker and Kwack (BK) medium [12]. At this stage, $0.5 \%$ agar, $25^{\circ} \mathrm{C}$ and the incubation duration of $3 \mathrm{~h}$ were used for both species.

The incorporation of PEG in the optimized medium as well as the interaction genotype $\times$ PEG had no significant effects on $D$. rotundata pollen germination percent (Table 3 ). However, significant effects of the genotype $(p=0.004)$, PEG application $(p=0.02)$ and the interaction PEG $\times$ genotype $(p=0.04)$ were recorded for $D$. alata. The presence of PEG in the medium significantly reduced $D$. alata pollen germination ability by $67-75 \%$ (Table 3 ).

Table 3. Effects of the polyethylene glycol (PEG) on germination percent of yam pollen.

\begin{tabular}{cccc}
\hline Species & Genotype & Treatment & Pollen Germination (\%) \\
\hline \multirow{3}{*}{ D. alata } & TDa1662006 & Without PEG & $45.0^{\mathrm{a}}$ \\
& & With PEG & $15.0^{\mathrm{b}}$ \\
\cline { 2 - 4 } & \multirow{2}{*}{ TDa1662010 } & Without PEG & $4.0^{\mathrm{b}}$ \\
& & With PEG & $1.0^{\mathrm{b}}$ \\
\hline \multirow{3}{*}{ D. rotundata } & TDr1621003 & Without PEG & $45.0^{\mathrm{ns}}$ \\
& & With PEG & $30.0^{\mathrm{ns}}$ \\
& \multirow{2}{*}{ TDr1614205 } & Without PEG & $8.0^{\mathrm{ns}}$ \\
& & With PEG & $13.0^{\mathrm{ns}}$ \\
\hline
\end{tabular}

ns = no significant differences among the means for D. rotundata species. Means followed by the same letter in the column do not differ by the LSD test at a $5 \%$-value threshold.

Comparing the optimized media with the starting Brewbaker and Kwack (BK) medium showed no significant differences regardless of the genotype and species. We also discovered that the established culture medium for $D$. rotundata was unsuitable for $D$. alata. For instance, the $D$. alata germination rate was significantly lower when grown on the medium optimized for D. rotundata (7.1\%) compared to its performance on the medium optimized for D. alata $(24.5 \%)$ and the BK medium $(20.0 \%)$. 


\subsection{Correlations Between In Vitro Germination and In Vivo Fertilization}

To assess the accuracy of the in vitro pollen germination in predicting fruit set, we added to the four genotypes in the previous steps, other pollen parents which were readily available at the time of this validation step. We found that although the female parents cross-compatibility highly influenced the in vivo fertilization, the in vitro germination test predicted the percentage fruit set at 25.2 to $79.7 \%$ and 26.4 to $59.7 \%$ accuracy for $D$. rotundata and D. alata genotypes, respectively (Table 4 ). The schematic presentation of the optimized protocol is provided in Figure 6.

Table 4. Hand pollination success vs. in vitro pollen germination.

\begin{tabular}{|c|c|c|c|c|c|}
\hline Species & $\begin{array}{l}\text { Pollen } \\
\text { Parent }\end{array}$ & $\begin{array}{l}\text { Female } \\
\text { Parents }\end{array}$ & $\begin{array}{c}\text { Successful } \\
\text { Fruit Set }(\%)\end{array}$ & $\begin{array}{c}\text { Pollen } \\
\text { Germination (\%) }\end{array}$ & $\begin{array}{c}\text { Prediction } \\
\text { Accuracy (\%) * }\end{array}$ \\
\hline \multirow{4}{*}{ D. rotundata } & TDr1621001 & $\begin{array}{c}\text { TDr1620009 } \\
\text { TDr1669010 } \\
\text { TDr1620004 } \\
\text { Mean }\end{array}$ & $\begin{array}{c}0.0(38) \\
11.0(148) \\
1.7(57) \\
4.2(243)\end{array}$ & 16.8 & 25.2 \\
\hline & TDr1621012 & $\begin{array}{l}\text { TDr1601008 } \\
\text { TDr1620009 } \\
\text { TDr1669010 } \\
\text { TDr1620015 } \\
\text { Mean }\end{array}$ & $\begin{array}{c}31.5(158) \\
18.1(68) \\
45.5(126) \\
0.0(17) \\
23.8(369)\end{array}$ & 37.1 & 64.1 \\
\hline & TDr1621003 & $\begin{array}{c}\text { TDr1620009 } \\
\text { TDr1621009 } \\
\text { TDr1620029 } \\
\text { TDr1669010 } \\
\text { TDr1620015 } \\
\text { TDr1620004 } \\
\text { Mean }\end{array}$ & $\begin{array}{c}16.3(436) \\
9.4(87) \\
0.0(48) \\
26.9(26) \\
20.0(183) \\
0.0(113) \\
12.1(893)\end{array}$ & 37.5 & 32.3 \\
\hline & TDr1614205 & TDr1680036 & $13.3(117)$ & 10.6 & 79.7 \\
\hline \multirow[b]{2}{*}{ D. alata } & TDa1662006 & $\begin{array}{c}\text { TDa160303 } \\
\text { TDa1662002 } \\
\text { Mean }\end{array}$ & $\begin{array}{l}50.7(311) \\
35.1(233) \\
46.0(544)\end{array}$ & 27.5 & 59.7 \\
\hline & TDa1662010 & $\begin{array}{c}\text { TDa160303 } \\
\text { TDa161001 } \\
\text { TDa1662002 } \\
\text { TDa1662003 } \\
\text { TDa1680003 } \\
\text { Mean }\end{array}$ & $\begin{array}{c}29.7(298) \\
60.6(19) \\
32.0(61) \\
9.5(24) \\
22.6(416) \\
29.3(818)\end{array}$ & 7.7 & 26.4 \\
\hline
\end{tabular}




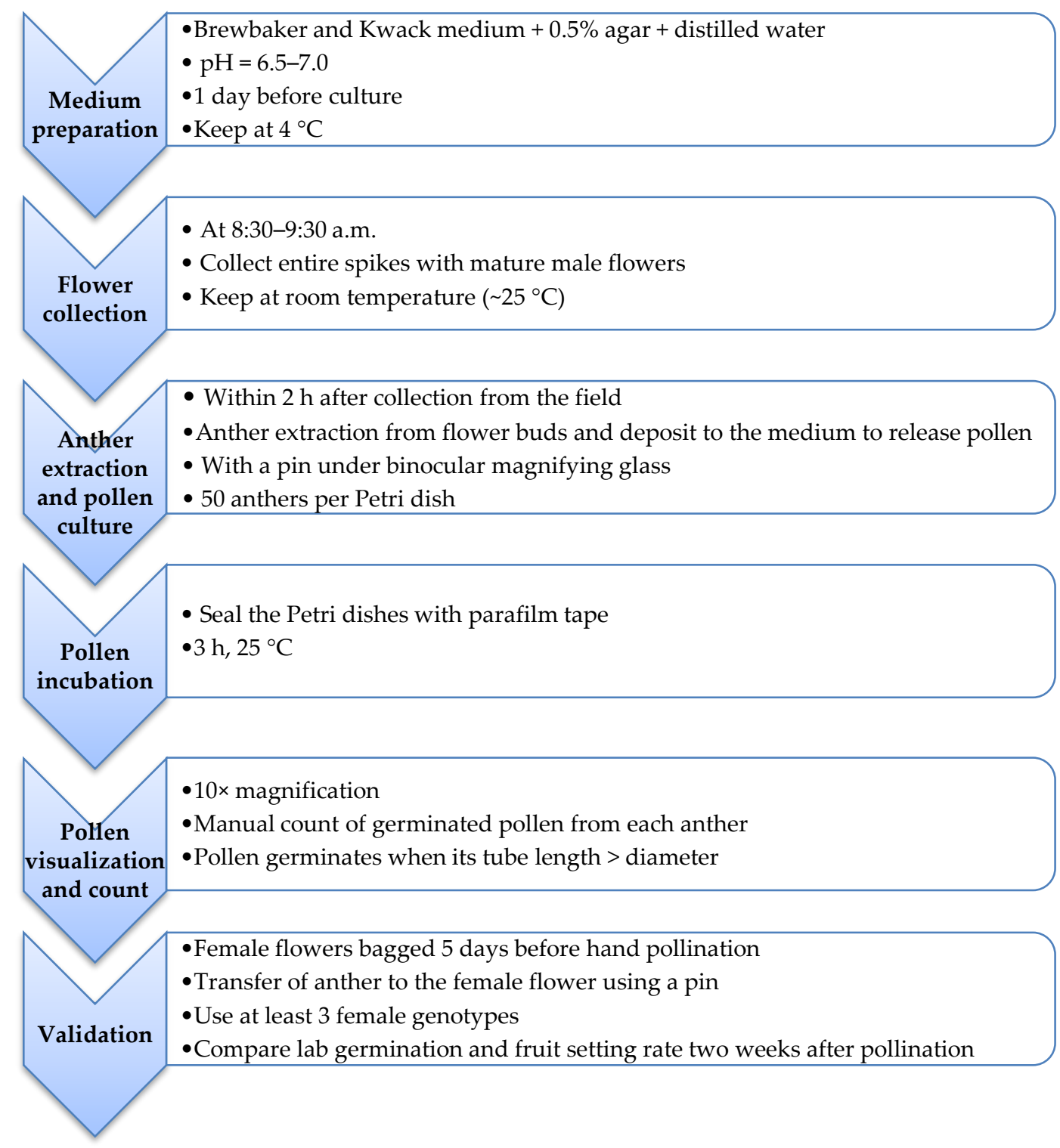

Figure 6. Schematic presentation of the optimized protocol for in vitro pollen germination testing in Dioscorea spp.

\section{Discussion}

A reliable pollen germination testing method is crucial for improving the breeding practices and the pollination efficiency in the low and asynchronous flowering yam plant. The literature shows that pollen germination depends on species, cultivar, and growing conditions [13]. The present study assessed the effects of growing conditions and medium composition on the pollen germination of $D$. rotundata and D. alata genotypes. Based on this study, the collected pollen should be used within $2 \mathrm{~h}$ for maximum results, as the viability is significantly reduced after $3-4 \mathrm{~h}$. The screening of a large number of genotypes will be challenging as it takes 8-12 min for culturing pollen in a single Petri dish. Moreover, the recommended time for yam pollen collection is limited to the morning hours (8-11 a.m.) [8]. Rapid viability testing methods will, therefore, be necessary if high throughput phenotyping is desired for yam pollen. The pollen germination protocol optimized in this study will serve as the basis for calibrating other methods such as staining, impedance and optical flow cytometry as well as automated pollen count [6].

The extent of in vitro pollen germination was primarily associated with the genotype and growing conditions rather than the medium composition for both yam species. This finding ascertained the suitability of the standard Brewbaker and Kwack (BK) medium 
for yam species without optimizing the sucrose, calcium nitrate and boric acid. The BK medium was successfully tested on 86 species from 79 genera and 39 families [12]. This study also endorsed $25^{\circ} \mathrm{C}$ as the optimal germination temperature for yam species, as it was also recommended on most plant species [11]. However, the D. rotundata had an extensive germination temperature range $\left(15-35^{\circ} \mathrm{C}\right)$ compared to $D$. alata genotypes. The finding from this study suggests using the semi-solidified medium rather than the liquid (hanging drop without agar) medium. Silva et al. [14] showed that the agar plays several roles in the germination medium: it promotes the solidification and the osmotic equilibrium of the culture medium, ensures a constant relative humidity, and facilitates the incorporation of nutrients, aiding the formation of the pollen tube. In opposition to previous yam pollen studies which used $0.7 \%$ agar, this study found consistently better results with $0.5 \%$ agar. This concentration may have favored high water and nutrient absorptions for the pollen tube's optimal formation and growth [14]. The absence of full information on the agar type, autoclaving, and handling procedures used in previous pollen studies on yam makes it difficult to conclude whether observed positive results with $0.5 \%$ agar are only attributed to the agar concentration or other handling procedures. Our results supported Daniel et al. [8]'s method for the $3 \mathrm{~h}$ incubation duration as no significant differences were found with the $18 \mathrm{~h}$ incubation duration used by Akoroda [9]. Although some yam pollen grains germinated after $3 \mathrm{~h}$, the initial trends remained unchanged at $18 \mathrm{~h}$. This study does not recommend using polyethylene glycol (PEG) on culture medium as it reduced the pollen germination percent.

Unlike Akoroda [9] and Daniel et al. [8], the in vitro germination percentage was consistently higher than the in vivo fruit set for $D$. rotundata. Several environmental factors (rainfall, relative humidity, temperature, sunshine, etc.), stigma receptivity and crosscompatibility barriers affect the successful pollination and fruit set under field conditions, although viable pollen was used [6,7]. These factors often result in low correlations between laboratory estimates and in vivo fertilization data. Previous studies on yam found no clear trend in predicting field fruit set using in vitro germination estimates, probably because the used medium and growing conditions, adapted from other crop species, were not suitable for optimum yam pollen germination $[8,9,15]$. Our study showed a positive correlation trend between pollen germination percent and the fruit set in field after hand pollination for both $D$. rotundata and $D$. alata genotypes. It was, thus, possible to discriminate the genotypes based on pollen viability status using in vitro testing data. The positive relationship between in vitro germination and in vivo fruit set was also reported by a study on yam [10] and other plant species [11].

Although our protocol could rank the genotypes, determining the exact germination percents was mostly under the weather conditions' effects before and during the pollen collection. This could explain fluctuations in genotype means without affecting the ranking. Compared to the pollen germination ranges from the yam literature $(0.3-85 \%$ for $D$. rotundata and $20-98 \%$ for D. alata [6]), the in vitro germination percent in this study seldom surpassed $45 \%$, regardless of the species and treatment. This could be attributed to the hybrid nature of plant materials used in this study. Alexander [16] observed reduced pollen viability of hybrids compared to either parent pollen in ornamental plants.

\section{Materials and Methods}

\subsection{Plant Material}

Two genetically known and profusely flowering male genotypes of D. rotundata (TDr1621012 and TDr1655018) and two of D. alata (TDa1662010 and TDa1662006) were selected for this study. They were all breeding lines and diploids. After flowering has ceased for the two D. rotundata genotypes, they were replaced by relative genotypes (TDr1621003 and TDr1614205) to complete the experiment. Past experiences have shown that the pollen of yam genotypes from same crossing families tended to behave alike. Female parents readily available at the in vivo fertilization step were sourced from yam crossing blocks established in April 2020 on a research field at the International Institute 
of Tropical Agriculture (IITA), Ibadan, Nigeria $\left(7^{\circ} 29^{\prime} \mathrm{N}\right.$ and $\left.3^{\circ} 54^{\prime} \mathrm{E}\right)$. The list of female genotypes used in this study is presented in Table 5 . They were all breeding lines, diploids and with good crossability history. Optimum crop husbandry practices such as remoulding of ridges, timely weeding, training of vines on stakes, and irrigation were applied in the crossing blocks, as needed, during the growing season. No fertilizer was applied.

Table 5. Female genotypes used for in vivo fertilization experiment.

\begin{tabular}{lc}
\hline Species & Genotypes \\
\hline & TDa160303 \\
D. alata & TDa161001 \\
& TDa1662002 \\
& TDa1662003 \\
& TDa1680003 \\
\hline & TDr1601008 \\
& TDr1620004 \\
& TDr1620009 \\
& TDr1620015 \\
& TDr1620029 \\
& TDr1621009 \\
& TDr1669010 \\
\end{tabular}

\subsection{Male Flower Harvest and Pollen Extraction}

In Nigeria where IITA yam crossing blocks are established, the flowering window extends from July-September and September-November for D. rotundata and D. alata species, respectively. Pollen germination testing was, thus, conducted in those time intervals. On the day of pollen germination experiments, recently opened male flowers were collected between 8:30 and 9:30 a.m. when the weather condition was still cool. Flowers were harvested and kept in well-labeled plastic vials and deposited in a basket for transport. Since the laboratory was close to crossing blocks and the weather was still cool, no particular preservation measure (in terms of temperature or humidity) was taken during transport from the field to the laboratory.

Except for the experiment testing the effect of delay between pollen collection and culture, the harvested pollen was used within $2 \mathrm{~h}$ after collection from field. Due to the tiny size and the sticky nature of yam pollen grains, anthers were removed from the flower buds and deposited on the medium to release pollen. A binocular magnifying glass and a pin facilitated the anther removal and transfer. Since not all yam anthers contain pollen, a total of 50 anthers were deposited in each Petri dish to ensure availability of sufficient pollen grains for scoring.

\subsection{Assessment of the Optimal Growth Conditions for In Vitro Pollen Germination}

Growth conditions tested were mainly the effect of delay in pollen use, incubation temperature and duration, and the medium viscosity. For this experiment, we used the Brewbaker and Kwack (BK) medium (i.e., $10 \%$ sucrose, 100 ppm $\mathrm{H}_{3} \mathrm{BO}_{3}, 300 \mathrm{ppm}$ $\mathrm{Ca}\left(\mathrm{NO}_{3}\right)_{2} \cdot 4 \mathrm{H}_{2} \mathrm{O}, 200 \mathrm{ppm} \mathrm{MgSO}_{4} \cdot 7 \mathrm{H}_{2} \mathrm{O}, 100 \mathrm{ppm} \mathrm{KNO}_{3}$ in distilled water) [12]. The $\mathrm{pH}$ was adjusted to 6.5 by adding $\mathrm{HCl}$ (acid) or $\mathrm{NaOH}$ (base) to the medium using a magnetic stirrer and a digital $\mathrm{pH}$-meter. Solutions were then autoclaved for $15 \mathrm{~min}\left(121^{\circ} \mathrm{C}\right.$, $1 \mathrm{~atm}$.), cooled for $30 \mathrm{~min}$, pipetted into $60 \mathrm{~mm}$ plastic Petri dishes and stored at $4{ }^{\circ} \mathrm{C}$ in a refrigerator for use by the next day.

To test the effect of the medium viscosity, two types of medium were prepared; the liquid or hanging drop without agar and the semi-solidified medium with three agar levels $(0.5 \%, 0.75 \%$ and $1 \%)$. The agar used in this study is of the Glentham Life Sciences Trademark (Corsham, United Kingdom, $\left.\left(\mathrm{C}_{12} \mathrm{H}_{18} \mathrm{O}_{9}\right)_{\mathrm{n}}\right)$. Effects of the delay in use of collected pollen were assessed using five time intervals: $<1 \mathrm{~h}, 1-2 \mathrm{~h}, 2-3 \mathrm{~h}, 3-4 \mathrm{~h}$, and $4-5 \mathrm{~h}$. 
Sufficient male flower sample was collected once in the morning and kept on the laboratory bench at ambient conditions $\left(25^{\circ} \mathrm{C}\right)$. The incubation temperature and duration effects were evaluated by incubating cultivated Petri dishes for 3 and $18 \mathrm{~h}$ under 15,25 and $35^{\circ} \mathrm{C}$ (we used simultaneously three different incubators).

\subsection{Medium Composition Optimization}

After determining the optimal medium type (liquid or semi-solidified), agar concentration, incubation duration and temperature, and the best time interval between pollen collection and use; the medium composition was then optimized. As suggested by the literature, the single-factor optimization experiments for medium composition focused on boric acid, calcium nitrate, sucrose and pH. The Brewbaker and Kwack medium (BK) was used as the starting medium and was step-wisely modified to find the optimum media for Dioscorea spp. Boric acid (50, 75, 100, 125 and $150 \mathrm{ppm})$, calcium nitrate (150, 225, 300, 375 and $450 \mathrm{ppm})$ and sucrose $(5 \%, 7.5 \%, 10 \%, 12.5 \%$ and $15 \%)$ were tested at $50 \%, 75 \%, 100 \%$, $125 \%$ and $150 \%$ of the initial concentrations in the Brewbaker and Kwack (BK) medium.

Culture media with optimized concentrations were then tested at different $\mathrm{pH}(5.5,6.0$, $6.5,7.0$ and 7.5). At the end of the medium optimization process, the effects of polyethylene glycol (PEG 8000, Sigma Chemical Co, St. Louis, MO, USA) at a concentration of $60 \mathrm{~g}$ $\mathrm{L}^{-1}$ were assessed. PEG was applied on the medium after autoclaving but before the complete solidification of the medium. Once the PEG was added to the medium, the flask was shaken gently to ensure homogeneity (equal distribution) of the solution before the medium solidified. It was, thus, applied on the medium after autoclaving but before pipetting in Petri dishes.

As for the previous steps, solutions were autoclaved for $15 \mathrm{~min}\left(121^{\circ} \mathrm{C}, 1 \mathrm{~atm}\right.$.), cooled for $30 \mathrm{~min}$, pipetted into $60 \mathrm{~mm}$ plastic Petri dishes and stored at $4{ }^{\circ} \mathrm{C}$ in a refrigerator for use by the next day. The Petri dishes containing pollen were sealed prior and during incubation using a parafilm tape. The relative humidity in the incubator was not recorded. The pollen germination was in dark for all experiments (used incubators had light bulb but which automatically switched off upon closure of the incubator solid outer door).

\subsection{Pollen Germination Scoring}

After the incubation, a fluorescence microscope (Olympus BX51, Tokyo, Japan) was used to visualize at $10 \times$ magnification and to count the germinated pollen grains from each anther manually. As suggested by Dafni and Firmage [7], pollen grains were considered germinating when their tubes elongated to a length that was at least their diameter.

\subsection{In Vivo Fertilization}

To determine the correlation between the in vitro germination and in vivo fertilization methods, the average performance of each pollen parent in crosses with distinct female genotypes was recorded. At flowering, female flowers were bagged with thrips-proof cloth bags 5 days before pollination. Hand pollination was then carried out and pollinated flowers were bagged for two weeks. At the validation step, male flowers used for pollen germination in the laboratory were sourced from the same individuals providing pollen for hand pollination in the field. The number of female flowers pollinated in a crosscombination depended on the availability of either mature male or receptive female flowers on the day of crossing. Moreover, some female genotypes produced more flowers than others, and thus, the number of flowers pollinated per female genotype was not identical for all involved females. Due to existing cross-compatibility barriers in yam breeding, cross-combinations were decided based on crossability history of both male and female genotypes. All the crosses were performed in the morning hours (8 a.m. to 12 noon). Successful fruit set was evaluated two weeks after hand pollination. It consisted of opening the cloth bags and manually counting the number of fruits developed on a spike. The percentage fruit setting rate was then calculated as follows: 


$$
\text { Fruit setting rate }(\%)=\frac{\text { Number of fruits set }}{\text { Number of flowers pollinated }} \times 100
$$

\subsection{Data Analysis}

Experiment on testing effects of delay in culture after pollen collection from the field had five replications and 50 pollen grains scored per replication, making a total of 250 pollen grains scored per time interval. After discovering that a yam pollen sample was significantly losing viability after $2 \mathrm{~h}$, we reduced the number of replications for the following steps to ensure pollen culture for every experiment was completed within $2 \mathrm{~h}$ after pollen collection from the field. Therefore, all the laboratory experiments for testing pollen growing conditions and the medium composition optimizations were conducted in two replications for each treatment. A total of 50 pollen grains were scored per replication, making the overall number to 100 pollen grains scored for each treatment. It is noteworthy that yam pollen is sticky to the anther and it was requiring 8-12 min for extracting and culturing anthers with pollen in a single Petri dish.

Data on the effect of delay in pollen culture, medium composition and growth condition optimizations were subjected to variance analysis and the means were separated by Fisher's least significant difference (LSD) test at 5\% $p$-value threshold, using the lme4 package implemented in $\mathrm{R}$ software [17]. The in vitro germination test's prediction accuracy was calculated by comparing the germination percent (expected value) and the overall in vivo fruit set percent (observed value) for each male parent in a series of hand pollinations.

\section{Conclusions}

This study showed that the yam pollen germination is primarily influenced by the genotype and the growing conditions such as the incubation temperature, the medium viscosity and time to use. The Brewbaker and Kwack's medium used in previous yam pollen studies is still suitable without optimizing the boric acid, calcium nitrate, sucrose and $\mathrm{pH}$. This protocol provides a possibility of ranking genotypes and predicting the in vivo fruit set using in vitro pollen germination information. It is, therefore, filling the gap which existed in yam breeding by providing an optimized protocol for in vitro testing of yam pollen germination. It will also serve as the basis for calibrating rapid pollen viability testing methods to allow high throughput pollen phenotyping for yam breeding programs.

Author Contributions: A.A., J.M.M. and P.A.A. designed the experiment. J.M.M. did data collection. P.A.A. and J.M.M. did data analysis. J.M.M. and P.A.A. drafted the manuscript with inputs from A.A. R.A. and M.O.A. contributed in writing up and revision. M.O.A., P.A.A. and A.A. did supervision. All the authors have read the last version and approved its submission. All authors have read and agreed to the published version of the manuscript.

Funding: The funding support from the Bill and Melinda Gates Foundation (BMGF) through the AfricaYam project of the International Institute of Tropical Agriculture (IITA) (OPP1052998) is acknowledged. The first author is grateful for the scholarship granted by the African Union Commission for his Ph.D. studies at the Pan African University-Institute of Life and Earth Sciences (PAULESI).

Institutional Review Board Statement: Not applicable.

Informed Consent Statement: Not applicable.

Data Availability Statement: All the data is contained within the article.

Acknowledgments: We are grateful for the technical support and practical experiences shared by the IITA yam breeding staff. We particularly recognize Theresa Olusola and Alex Edemodu for the lab assistance, the participation in data collection, and comments on this manuscript.

Conflicts of Interest: The authors declare no conflict of interest. Mention of trade names of commercial products in the publication is solely for the purpose of providing specific information and does not imply recommendation or endorsement by the IITA. 


\section{References}

1. Price, E.J.; Drapal, M.; Perez-Fons, L.; Amah, D.; Bhattacharjee, R.; Heider, B.; Rouard, M.; Swennen, R.; Becerra Lopez-Lavalle, L.A.; Fraser, P.D. Metabolite database for root, tuber, and banana crops to facilitate modern breeding in understudied crops. Plant J. 2020, 101, 1258-1268. [CrossRef] [PubMed]

2. Darkwa, K.; Olasanmi, B.; Asiedu, R.; Asfaw, A. Review of empirical and emerging breeding methods and tools for yam (Dioscorea spp.) improvement: Status and prospects. Plant Breed. 2020, 139, 474-497. [CrossRef]

3. FAO FAOSTAT. Available online: http://www.fao.org/faostat/en/\#data/QL (accessed on 1 December 2020).

4. Tamiru, M.; Natsume, S.; Takagi, H.; White, B.; Yaegashi, H.; Shimizu, M.; Yoshida, K.; Uemura, A.; Oikawa, K.; Abe, A.; et al. Genome sequencing of the staple food crop white Guinea yam enables the development of a molecular marker for sex determination. BMC Biol. 2017, 15, 1-20. [CrossRef] [PubMed]

5. Agre, P.; Nwachukwu, C.; Olasanmi, B.; Obidiegwu, J.; Nwachukwu, E.; Adebola, P.; De Koeyer, D.; Asrat, A. Sample Preservation and Plant Sex Prediction in White Guinea yam (Dioscorea rotundata Poir.). J. Appl. Biotechnol. Rep. 2020, 7, $145-151$.

6. Mondo, J.M.; Agre, P.A.; Edemodu, A.; Adebola, P.; Asiedu, R.; Akoroda, M.O.; Asfaw, A. Floral Biology and Pollination Efficiency in Yam (Dioscorea spp.). Agriculture 2020, 10, 560. [CrossRef]

7. Dafni, A.; Firmage, D. Pollen viability and longevity: Practical, ecological and evolutionary implications. Plant Syst. Evol. 2000, 222, 113-132. [CrossRef]

8. Daniel, I.O.; Ng, N.Q.; Tayo, T.O.; Togun, A.O. Wet-cold preservation of West African yam (Dioscorea spp.) pollen. J. Agric. Sci. 2002, 138, 57-62. [CrossRef]

9. Akoroda, M. Long-term storage of yam pollen. Sci. Hortic. 1983, 20, 225-230. [CrossRef]

10. Ng, N.Q.; Daniel, I.O. Storage of pollens for long-term conservation of yam genetic resources. In Cryopreservation of Tropical Plant Germplasm: Current Research Progress and Application; Englemann, F., Tagaki, H., Eds.; JIRCAS/IPGRI Co-Publication: Tsukuba, Japan, 2000; pp. 136-139.

11. Volk, G.M. Collecting Pollen for Genetic Resources Conservation. In Collecting Plant Genetic Diversity: Technical Guidelines 2011 Update; Guarino, L., Ramanatha, V.R., Goldberg, E., Eds.; Bioversity International: Rome, Italy, 2011; pp. 1-10.

12. Brewbaker, J.L.; Kwack, B.H. The essential role of calcium ion in pollen germination and pollen tube growth. Am. J. Bot. 1963, 50, 859-865. [CrossRef]

13. Impe, D.; Reitz, J.; Köpnick, C.; Rolletschek, H.; Börner, A.; Senula, A.; Nagel, M. Assessment of Pollen Viability for Wheat. Front. Plant Sci. 2020, 10, 10. [CrossRef] [PubMed]

14. Silva, D.M.; Zambon, C.R.; Techio, V.H.; Pio, R. Floral characterization and pollen germination protocol for Castanea crenata Siebold \& Zucc. S. Afr. J. Bot. 2020, 130, 389-395.

15. Akoroda, M.O. Pollen management for controlled hybridization of white yam. Sci. Hortic. 1985, 25, 201-209. [CrossRef]

16. Alexander, L.W. Optimizing pollen germination and pollen viability estimates for Hydrangea macrophylla, Dichroa febrifuga, and their hybrids. Sci. Hortic. 2019, 246, 244-250. [CrossRef]

17. R Development Core Team. R: A Language and Environment for Statistical Computing. R Foundation for Statistical Computing: Vienna, Austria, 2018. 